\title{
Entrepreneurship studies: the case for radical change
}

Book or Report Section

Accepted Version

Casson, M. (2019) Entrepreneurship studies: the case for radical change. In: Audretsch, D. B., Lehmann, E. E. and Link, A. N. (eds.) A Research Agenda for Entrepreneurship and Innovation. Elgar Research Agendas. Edward Elgar, Cheltenham, pp. 208-218. ISBN 9781788116008 Available at http://centaur.reading.ac.uk/84652/

It is advisable to refer to the publisher's version if you intend to cite from the work. See Guidance on citing.

Publisher: Edward Elgar

All outputs in CentAUR are protected by Intellectual Property Rights law, including copyright law. Copyright and IPR is retained by the creators or other copyright holders. Terms and conditions for use of this material are defined in the End User Agreement. 


\section{www.reading.ac.uk/centaur}

\section{CentAUR}

Central Archive at the University of Reading

Reading's research outputs online 
Entrepreneurship studies: the case for radical change Mark Casson

University of Reading

E-mail:m.c.casson@reading.ac.uk 


\begin{abstract}
Entrepreneurship studies needs to re-engage with classic disciplines such as economics, history, statistics, geography and sociology. Fifty years ago there was a widely agreed methodology for social science research based on techniques developed by these disciplines. They analysed the evolution of complex social and economic systems in terms of rationality, efficiency, competition, co-operation, equilibrium and stability. Today their insights are misunderstood and increasingly ignored. Entrepreneurship studies needs to go back in order to go forward: it must re-engage with traditional techniques in order for research to progress in future.
\end{abstract}

KEYWORDS: ENTREPRENEURSHIP; METHODOLOGY; SOCIAL SCIENCE; PROCESS; DYNAMICS 


\section{Introduction}

This chapter advances a challenging and potentially unpopular proposition: namely that entrepreneurship studies needs to re-engage with classic social science disciplines such as economics, history, statistics, geography and sociology if it is to progress. It may be a branch of business and management studies, but it cannot thrive solely in that environment. The classic social science disciplines provide essential techniques of analysis and, in their traditional form, share a methodology which helps to guarantee the quality of published research. In many areas of entrepreneurship studies the techniques employed are too simple, and the methodologies employed too varied, to guarantee the quality of research.

Journal editors maintain that new research must build on the foundations of the old. This would be fine if those foundations were sound. But certain parts of entrepreneurship studies are, arguably, like houses built upon sand, to use a Biblical analogy; they do not provide a secure basis for future research. Compared to early work in the field, many recent papers appear to be based on weak technique and poor methodology It is necessary to dig down further, and, like an archaeologist, go back in time, until secure foundations for future research are reached. That time was fifty years ago or more, it is suggested here.

This proposition is a special case of a more general proposition, namely that business and management studies as a whole faces a crisis of academic credibility. Within this field, international business studies, organizational studies and leadership studies face similar problems (Casson, 2018). Each has an enormous literature, comprising many papers, each of which contains an extensive literature review. Each researcher cites other researchers, who quickly amass an impressive list of citations. Most citations are to papers in the same field, rather than to relevant papers in other fields. Each field becomes a silo; each silo reinvents the same set of concepts that are used in other silos, but gives those concepts a different name (Goldsmith, Komlos and Gold, 2001). If a researcher in one field consults the literature in another field they may learn very little because what they will discover is the same ideas repackaged under different names. Anyone who is new to the field simply gets confused.

\section{Unified social science: a missed opportunity?}

Fifty years ago, by contrast, there was greater interaction between social science disciplines. It was believed that it was possible to construct a unified social science that would command the same respect as the natural sciences. It would not be the same as a natural science because it would focus, not on atoms and atomic structure, but on people and their social structures. Politics would study how people governed themselves, economics how they made a living, psychology how people made decisions, linguistics how people communicated and sociology how people interacted within the family and other social groups. The post-war business schools were seen as a useful laboratory for piloting the development of this unified social science. Bringing together people from different social sciences to study business would demonstrate how different disciplines could work together to develop a better understanding of business, and to promote improved business performance. The lessons learned from interdisciplinary research on business could then be rolled out to other subject areas. 
A promising start was made. Most of the scholars recruited to business schools had been trained in one of the traditional disciplines. With the exception of the Marxists, there was general agreement on the kind of methodology that would guarantee the reliability of research results. Compliance with this methodology was believed to guarantee the reliability of research results. The methodology had general consent and was perceived as a 'gold standard' for the quality of published research.

\section{Traditional research methodology}

The methodology which guided research at this time may be summarised as follows (Rescher, 1977). It had four main elements.

Results should be meaningful.

- A small number of key concepts should be employed. Each concept should be carefully defined, to avoid misleading connotations (e.g. 'capital' has many possible meanings, and using it in different ways within the same discussion can create confusion).

- The scope of the study should be set out and the context described in detail (e.g. the population of firms from which a sample has been taken). This avoids spurious generalisations from specific results.

- The results should be written up precisely and grammatically to make their meaning clear (e.g. excessive use of jargon can mislead)

Evidence should be reliable.

- A research study may offer new evidence or re-work existing evidence.

- New sources widen the evidence base and leads to more robust results. But they need to be carefully validated (e.g. Is the sample biased? Has data entry been checked for accuracy?)

- Research should be replicable. Replication is a valuable check on previous work.

Interpretation should be rigorous.

- Evidence does not speak for itself; it needs to be interpreted. This requires a theory. A theory consists of one or more hypotheses. Hypotheses should be deduced from a common set of assumptions.

- Assumptions should be made explicit. This facilitates discussion and debate.

- A theory should be simple. For this reason the assumptions should exclude those aspects of the problem that do not relate directly to what the theory seeks to explain.

- A theory should have a clear logical structure. A good theory is a general theory; it effects economy of thought. Because it needs to apply to different situations it must include contingent factors (e.g. a general theory of entrepreneurship should take account of different forms of entrepreneurship)

- A theory should predict specific patterns in the evidence. Otherwise it cannot explain anything, and so the validity of the theory cannot be tested. 
Results should be relevant

- Research may satisfy personal curiosity (e.g. explaining anomalies or paradoxes). A culture of curiosity stimulates research. Research results should therefore be presented in an engaging and entertaining way to reach as wide an audience as possible.

- Researchers should engage with policy and practice by developing the practical implications of their results. But the ethical implications should be considered too.

Although this methodology is still pursued by some 'traditionalists' in the social sciences, its influence has declined, especially in businesses studies. It has lost ground to a range of 'modernist' methodologies.

\section{Modernist methodologies}

Modernist methodologies are characterised by concerns for pluralism (e.g toleration of minority opinions) and political correctness (e.g. avoiding demeaning descriptions of vulnerable social groups) They tend to favour research methods derived from the arts (e.g. literary criticism) rather than the sciences (e.g. neoclassical economics). Three of the most common modernist methodologists are examined below.

Free-thinking. According to free-thinkers, traditional methodology is an instrument of social power by which researchers are coerced into following a pseudo-scientific approach. Methodology should be a matter of personal choice, they affirm. Those who make similar personal choices should be free to associate together, creating special interest groups that publish their own journals and organise their own conferences. Members who gain faculty positions should seek to influence recruitment in their institution in order to create a cell with a critical mass of like-minded researchers.

Free-thinkers position themselves in opposition to the traditionalist elite, as they perceive it. Traditionalist publications are simply advocacy packaged in pseudo-scientific jargon, they claim. Economists produce forecasts that serve the interests of right-wing governments, while traditional business historians write business biographies that uncritically glorify the founders of the firm. Everything is advocacy, and the role of the scholar is to expose it. This has two unfortunate implications. First, free-thinkers tend to the use the literature as a source of evidence rather than looking behind the literature to re-examine the evidence on which it is based. 'Well, they would say that, wouldn't they?' is a common theme in free-thinking critiques of the literature. Secondly, if everything is advocacy then the best papers are the most compelling pieces of advocacy. Thus much of the free-thinking literature seems to exemplify the very thing it sets out to criticise; namely advocacy masquerading as research.

Inspirational thinking. Inspirational thinking is popular amongst entrepreneurship researchers. It is a form of intellectual innovation that can be made by people who lack the resources to make a practical innovation. Typically a problem with conventional theory is identified. This may arise from the discovery of some new phenomenon which, it is alleged, conventional theory cannot explain. The answer is a new concept, which appears to the researcher in a 'Eureka moment'. The concept is labelled by a buzz-word, and the word is 
linked to the name of the researcher who thought of it first. 'Strategy' is the oldest, and still the most popular, business buzz-word, it would seem, although 'vision', 'charisma', 'competence' and 'capability' are popular too. All of them apply, it seems, to the successful entrepreneur (Casson and della Giusta, 2013).

Ethical thinking. Ethical thinking combines elements of inspiration and free-thinking. While free-thinkers operate mainly through organised groups, and inspirational thinkers by individual initiative, ethical thinkers combine the two. Ethical thinkers prefer to test theories by the perceived morality of their policy implications rather than by the weight of evidence in their favour. They are particular active in gender studies and the emerging field of 'history of capitalism'. Traditional methodology, some argue, serves to legitimate the immoral. It normalises assumptions that property is private, action is rational, and profit is a reward. For ethical thinkers, the role of evidence is mainly as a source of supporting anecdotes for a chosen policy stance, rather than a valuable resource to be quarried for the information it contains. Contemporary ethical thinking is particularly important in gender studies and industrial relations, where traditionalists often seem to have little to say on high-profile policy issues.

\section{The switch to modernism}

Why have modernist methodologies become so popular? Three main factors may be identified.

Modernist methodologies make less use of formal models, mathematical methods and advanced statistical techniques. They make a research career accessible to a wider range of people. The first generation of scholars recruited to post-war business schools mostly came from traditional disciplines. Business economists developed theories of competitive strategy, sociologists developed theories of managerial bureaucracy, statisticians developed theories of inventory management and process control, while business historians researched the 'managerial revolution' and the apparent decline of family firms. They all had specialist research techniques at their disposal (Beissel-Durrant, 2004).

However, the rapid expansion of business schools in the 1970s and 1980s led to growing recruitment of scholars who had no training in a traditional discipline but had simply studied business from the outset. They were often teaching business practitioners from a variety backgrounds, and so lack of technique was no hindrance to a teaching career. As these new recruits rose to prominence in their profession, they changed the rules to reward themselves. They gained control of leading journals, and banished techniques derived from traditional disciplines. Journals began to publish papers that cited 'gurus' and 'thought leaders' rather than traditional researchers. The new generation marginalised the 'technocratic elite' that they replaced.

Modernist methodologies make less use of primary evidence. The first generation of business researchers compiled their own databases from business accounts, censuses of production, VAT registrations, and so on. They carried out in-depth face-to-face interviews with entrepreneurs. Today databases are downloaded off the internet, but the evidence, it seems, is 
rarely checked because there is so much of it. Meanwhile comprehensive interview programmes have been abandoned because many entrepreneurs can no longer spare the time. Research time is scarce for the academic too. Methods that rely on low-cost evidence produced by third parties are therefore preferable to traditional methods dependent on highcost evidence. Research continues to be published, but much of the evidence is of lower quality than before.

Finally, modernist methodologies generate results that are better adapted to mass dissemination. If the final stage of research is to write an executive summary or a press release, or give a radio interview then why bother with all the intervening complications? Why not devise a simple buzz-word, find a couple of anecdotes, and announce the result? You can then add a literature review and publish a paper that anyone can understand, and may get lots of cites.

This cavalier approach to evidence and authenticity has serious implications for the profession, however. In law and medicine evidence is crucial because a person's life may depend on it being right. Law and medicine are both traditional in their methodology. Both involve 'trials' which test alternative views in a highly structured manner. Legal trials, for example, are preceded by detective work, regulated by strict rules governing the admissability of evidence, involve the testimony of witnesses who are cross-examination before an independent third party, namely a judge. Trials between alternative views in business studies are, by comparison, relatively rare. By contrast conference debates on fundamental issues are uncommon, and speakers are rarely forced to engage with their opponents in a meaningful way.

\section{Economic dynamics of entrepreneurship: a traditionalist view}

Modernists, of course, do not explain their popularity in these terms. They focus on the alleged shortcomings of the traditional approach. They allege, for example, that traditional disciplines like economics are based on static equilibrium thinking and therefore ignore the dynamics of entrepreneurship. They claim that assumptions are absurd, being based on a form of perfect rationality that is incompatible with entrepreneurial decision-making. Above all, they claim to study 'process', which they say is fundamentally different studying an equilibrium state. By emphasising the shortcomings of the traditional approach, they divert attention from the shortcoming of their own approach, as outlined above.

These criticisms of the traditional approach represent 'outsider' criticism. They are criticisms of how a methodology appears to those who do not use it. They are not 'insider' criticism, expressed by those who understand traditional methodology and who are aware of its weaknesses in certain areas. Consider, for example, the assumption of perfect rationality mentioned above. If a research question concerns the personal psychology of the entrepreneur then then assumption is unhelpful because it assumes the answer before the question has been investigated. But if the question is 'How do businesses grow?' then it is less objectionable: it is likely that growing businesses are managed in a reasonably rational way because otherwise they would fail to grow. Managers of growing businesses may not be perfectly rational, but 
they are probably more rational than the managers of businesses that fail to grow. Thus the relevance of an assumption depends on the research question being asked: as noted earlier, the role of assumptions is to focus attention on factors that really matter in the context of the problem and to abstract from factors that do not.

Traditional methods do not ignore dynamics. Dynamics are critical to analysing the stability of a system. The stability of general equilibrium in a multi-market system, for example, is analysed in terms of changes in price that are driven, in speed and direction, by the magnitude of excess demand (Arrow and Hahn, 1971). In other words, the speed of market adjustment is governed by the deviation of prices from their equilibrium levels.

The difference between traditionalists and modernists is not that traditionalists ignore dynamics but that traditionalists believe that economic and social systems are mostly stable. Whenever the environment changes, the system changes, but it changes in a way that restores equilibrium. The system adapts, in other words. This process may take some time, but although the system is often out of equilibrium it is always tending towards one. Modernists, on the other hand, tend to argue that the system just evolves. One thing follows from another but there is little direction or purpose to it; anything can happen because evolution is blind.

But even biological evolution - a favourite source of modernist metaphors - has direction to it. Darwin's theory of natural selection is based, in part, on the Malthusian economic theory of competition (Vorzimmer, 1969). Natural selection weeds out inefficient species, so that in the long run only efficient species survive. Thus in the long run equilibrium prevails. As the environment changes, so the forces of natural selection change direction too.

The business system is just another system, from this perspective. Profit-seeking and competition are the economic drivers of the business system. Genuine opportunities make profits and fake opportunities make losses. Entrepreneurs with good judgement succeed and those with poor judgement fail. Good judgement tends to drive out bad judgement, and equilibrium prevails once the process is complete (Casson, 2003; Foss and Klein, 2012). Even 'disruptive' technological change is part of this process because it eliminates inefficiencies in technology and so helps good judgement to prevail.

In the context of entrepreneurship studies, Markov chains provide a useful tool of dynamic analysis. They are ideal for analysing the growth and decline of firms in an industry. They were first applied in this context by the Nobel Laureate Herbert Simon some fifty years ago, and are still used to day, but remain under-utilised in modern entrepreneurship studies (Ijiri and Simon, 1964).

Some simple examples of Markov chain analysis are described below (for a review see Stroock, 2014). The technical details have been omitted, but the methods are so well known that good accounts appear in Wikipedia and various mathematics teaching web-sites. Only the first of these examples has been extensively applied elsewhere. The other examples have a distinctive 'entrepreneurship' twist, and are therefore novel to some extent. Consider, therefore, a group of one hundred potential entrepreneurs who are looking for opportunities in an emerging industry. Suppose that each period on average 30 per cent of entrepreneurs who 
have not yet entered the industry believe that they have discovered an opportunity and decide to establish a firm. Entrepreneurs who have established a firm experience a failure rate of 10 per cent over the same period. In steady-state industry equilibrium the 30 per cent who enter must match the 10 per cent who fail, for otherwise the average number of firms will change Thus the population of entrepreneurs who manage firms must be three times the size of the population that do not. Thus in the steady state there are 75 firms and 25 entrepreneurs still searching for an opportunity (as either employees or unemployed). The industry is stable: whatever the initial number of firms, the industry will always converge on this steady state. The speed with which the industry converges is greater, the greater the volatility in the system. The speed of convergence is greater, the greater the sum of the firm formation rate and the firm failure rate. The speed of convergence is also greater the greater the divergence between the initial state and the steady state. In an emerging industry the initial state is one with no firms, and so the greater the number of steady state firms, the faster the industry will grow. All of this is easy to prove by elementary calculation. Furthermore the basic technique can be extended to far more complex, and therefore more realistic cases.

The second example presents an extension of this analysis that involves both large and small firms (see Figure 1). Small firms can grow large through innovation but they run a risk of failure if the market changes or they lack organisational capability. Decision-making is rational but myopic: small firms decide to innovate on the basis of information available to them while they are small and need to reconsider their decision in the light of experience. If they do not innovate they do not discover, but they do not consider every possible thing that they might discover before they innovate. It means that managers are rational in the way that they use the information they possess but they are not far-sighted and not perfectly informed. This may sound complicated, but in practice it is easy to analyse.

To vary the numbers, suppose that the birth rate of firms, driven by opportunity discovery, is lower at 20 per cent, and the failure rate for small firms is higher at 30 per cent. Only 10 per cent of small firms innovate to grow large, but these firms perform relatively well; their failure rate is only 10 per cent. These numbers have been chosen to generate a simple result: in the steady state half of the firms are small and half are large. The total number of firms is the same as before, however; three-quarters of the entrepreneurs are managing a firm and the other quarter are still looking for opportunities. Analysing the dynamics shows that the number of large firms is slow to grow to its steady state level because the innovation rate is relatively modest, and so convergence on the steady state is slower than before. By contrast, if the innovation rate were higher then the steady state number of large firms would be higher, the number of small firms would be lower, and convergence to the steady state would be faster.

The third example involves entrepreneurial learning. Learning can be analysed using the same technique, and so can serial entrepreneurship. All that is necessary is to postulate two kinds of firm founder: the novice entrepreneur, who has either never founded a firm or has learned nothing from a previous failure, and the experienced entrepreneur who has learned something from a previous failure. The two groups have different propensities to start a business and different propensities to fail. A new equilibrium condition requires that the 
number of experienced entrepreneurs setting up new firms is equal to the number of firms failures with learning. Once again the system is stable, and volatility (a high propensity to start new businesses and a high propensity to fail) leads to rapid convergence, as before. The solution of the equations determines both the numbers of novice and experienced entrepreneurs who are seeking an opportunity and also the numbers who are managing firms.

Anyone could have published these examples at any time in the last fifty years, but no one did so. In the light of the previous discussion, the most probable explanation is that no one was willing to publish them, and that this was so obvious that no-one even bothered to try. Had such a paper been submitted for publication the response may have been: 'There is nothing original; everyone knows this already'. While the first part of this criticism would be true, the second half is almost certainly false; many entrepreneurship scholars would not have known it already. Another response could have been classic outsider criticism: 'The approach is over-simplified and mechanistic; furthermore, it assumes that the propensities are stable over time, whereas we all know that they change.' Here the second part is true but the first is false; the approach is probabilistic rather than mechanistic, and therefore does justice to the notion that only statistical averages can be predicted where entrepreneurship is concerned. Simple techniques are always vulnerable to criticism because of the strong assumptions that they make. The solution is not less technique, but more sophisticated technique. But sophisticated technique is more difficult to understand, and requires the professional specialism of the traditional researcher.

\section{Conclusion}

The case for traditionalism has two main pillars. The first is the weaknesses of the modernist critique, and the second is the numerous positive advantages that it provides. Traditionalism is fundamentally progressive because it lays secure foundations on which future research can build. Traditional knowledge therefore accumulates over time, as knowledge should. It gives a field of study reputation with scholars working in related fields. Standardisation on methodology facilitates the movement of ideas across fields, whilst the reputation of each field gives scholars in other fields the confidence to import ideas.

Traditional methodology does not need to be modified to address the criticisms of modernists, because these criticisms are largely misplaced. The criticisms derive mainly from the fact that many modernists do not fully understand the techniques that they are criticising. There are many valid criticisms of traditional methods, but they are specific criticisms of the way that specific techniques are applied to specific issues; they are well-informed insider criticism and they provide a dynamic for self-improvement within traditional methodology. Entrepreneurship studies needs to address this methodological problem by recruiting more scholars with a command of traditional disciplines, and facing up to the serious limitation of modernist methodologies. 


\section{Figure 1: Decision tree analysis of firm foundation and survival}

Entrepreneur: They are seeking an opportunity. They are not managing a firm; they are an employee or are unemployed (state 0 )

Entrepreneur: They may believe that they have identified an opportunity: If so they decide to establish firm (enter state 1).

Reality: Entrepreneur in state 1 gains experience which they feed back into their next decision.

Entrepreneur: In the light of feedback the entrepreneur decides whether to scale up through innovation (to state 2), remain small (in state 1 ) or close down (re-enter state 0 ) Entrepreneur: They innovate and become the owner and manager of a large firm (enter state 2).

Reality: The entrepreneur gains experience to feed back into their next decision

Entrepreneur: In the light of feedback the entrepreneur decides whether to continue with a large firm (remain in state 2 ) or close down (enter state 0$)$

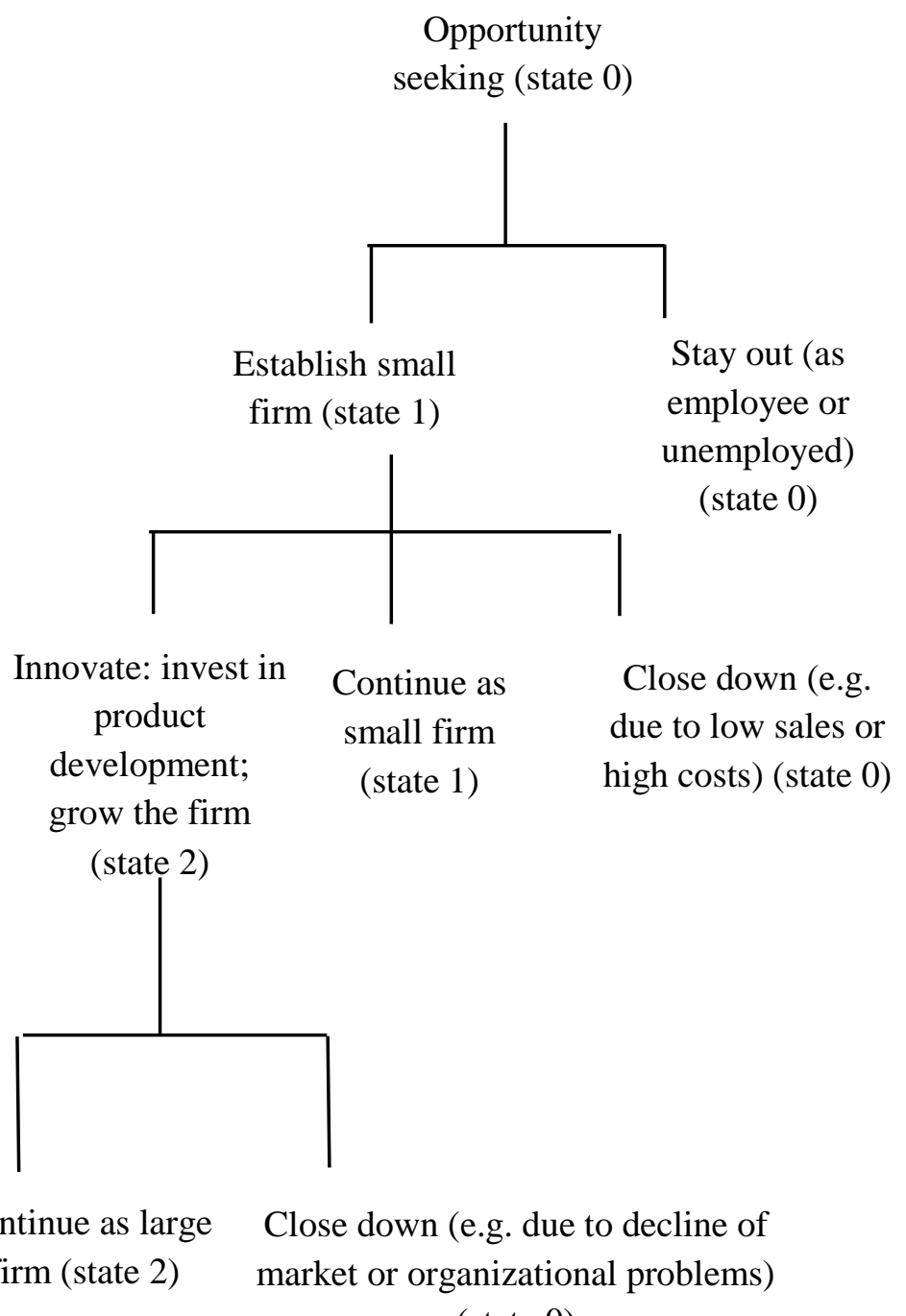

(state 0)

Note. These options relate to a given individual and the growth of a single firm. There are other options too, but their inclusion would complicate the figure. An entrepreneur may replicate a successful small firm start-up (perhaps with minor variations) and become a portfolio entrepreneur. An entrepreneur whose firm fails may not exit entrepreneurship but instead learn from their mistake and re-enter as a serial entrepreneur. An individual can, in principle, sell out at any stage, although in practice it is easier to sell a large successful firm (e.g. through a 


\section{References}

Arrow, Kenneth J. and Frank Hahn (1971) General Competitive Analysis, San Francisco: Holden-Day

Beissel-Durrant, Gabriele (2004) A Typology of Research Methods within the Social Sciences, London: Economic and Social Research Council, National Centre for Research Methods

Casson, Mark (2003) The Entrepreneur: An Economic Theory, $2^{\text {nd }}$. ed., Cheltenham: Edward Elgar

Casson, Mark (2018) The theory of international business: the role of economic models, Management International Review, 58(3), 363-387

Casson, Mark and Marina della Giusta (2013) Buzz words in international management education, in Tsang, D., Kazeroony, H.H. and Ellis, G. (eds.) Routledge Companion to International Business Education, Abingdon: Routledge, 344-357

Foss, Nicolai and Peter G. Klein (2012) Organizing Entrepreneurial Judgment: A New Approach to the Firm, Cambridge: Cambridge University Press

Goldsmith, John A., John Komlos and Penny Shine Gold (2001) The Chicago Guide to Your Academic Career, Chicago: University of Chicago Press

Ijiri, Yuji and Herbert A Simon (1964) Business firm growth and size, American Economic Review, 54 (2), 77-89

Rescher, Nicholas (1977) Methodological Pragmatism: A Systems-theoretic Approach to the Theory of Knowledge, New York: New York University Press

Stroock, Daniel W. (2014) An Introduction to Markov Processes, $2^{\text {nd }}$. ed. Berlin: Springer Vorzimmer, Peter (1969) Darwin, Malthus and the theory of natural selection, Journal of the History of Ideas, 30 (4), 527-542. 
